\title{
A meta para a crítica da/na mídia em abordagens metacríticas ${ }^{a}$ Critique of/in the media: the aim for metacritical approaches
}

\author{
IVAN PAGA NOT T T ${ }^{\mathrm{b}}$ \\ FIAM-FAAM Centro Universitário, Mestrado Profissional em Jornalismo. São Paulo - SP, Brasil \\ ROSANA DE LIMA SOARES \\ Universidade de São Paulo, Escola de Comunicações e Artes, Programa de Pós-Graduação em Meios \\ e Processos Audiovisuais. São Paulo - SP, Brasil
}

\begin{abstract}
RESUMO
A reflexão contemporânea sobre níveis distintos da crítica tem desenvolvido, a partir de perspectivas contrastantes, o conceito de metacrítica. Este artigo apresenta a possibilidade de se estabelecer uma crítica da cultura midiática por meio da metacrítica e a dificuldade peculiar em sugerir uma definição unívoca para o conceito, devido à sua multiplicidade e variabilidade, apresentando suas aplicações em diversos campos do conhecimento (especialmente a sociologia) e relacionando-o aos estudos das mídias. O texto propõe a metacrítica midiática como uma noção capaz de aglutinar análises sobre as práticas midiáticas, demonstrando sua pertinência em produções audiovisuais recentes.
\end{abstract}

Palavras-chave: Crítica da mídia, comunicação, metacrítica

\begin{abstract}
Diverging perspectives within the current reflection on different instances of critique have led to the concept of metacritique. This study discusses the possibility of metacritique as a critique of media culture, focusing on the peculiar difficulty of arriving at a consensual definition of this concept, due to its multiplicity and variability. It also discusses the concept's application within different fields of knowledge (sociology in special), discussing its relationship with media studies. It posits media metacritique as a concept able to bring together diverse media-practice analyses, demonstrating its relevance for recent audiovisual productions (television series and movies).
\end{abstract}

Keywords: Media critique, communication, metacritique

DOI:http://dx.doi.org/10.11606/issn.19S2-S160.v13i2p131-153
${ }^{\text {a } U m a ~ v e r s a ̃ o ~ i n i c i a l ~ d e s s a ~}$ pesquisa foi originalmente apresentada ao Grupo de Trabalho Cultura das Mídias do XXVII Encontro Anual da Compós, na Pontifícia Universidade Católica de Minas Gerais, em junho de 2018.

${ }^{\mathrm{b}}$ Professor doutor no Mestrado Profissional em Jornalismo do FIAM-FAAM Centro Universitário. Orcid: https:// orcid.org/0000-0001-5662-4240. E-mail: ivanpaganotti@gmail.com

${ }^{c}$ Professora livre-docente no Programa de PósGraduação em Meios e Processos Audiovisuais e no Departamento de Jornalismo e Editoração da Escola de Comunicações e Artes da Universidade de São Paulo. Bolsista Produtividade em Pesquisa CNPq. Orcid: https:// orcid.org/0000-0003-42509537. E-mail: rolima@usp.br 
INTRODUÇÃO: (IN)DEFINIÇÕES, CONVERGÊNCIAS E DIVERGÊNCIAS ENTRE (META)CRÍTICAS

LGUNS CONCEITOS PECULIARES - principalmente as ideias novas,
fruto de neologismos que ainda passam por processo de amadurecimento
- apresentam tamanha fertilidade para a análise dos processos de comunicação que acabam florescendo em diferentes ramos, apesar de continuarem a se conectar por um entroncamento comum. Nos estudos sobre linguagem, em particular, é importante analisar como essas novas formas de apresentar a realidade podem convergir ou divergir dos sentidos originais e das raízes linguísticas em que se sustentam. Este artigo procura mostrar os diferentes significados que se agregam ao conceito aparentemente unívoco de metacrítica, destacando seus pontos de confluência e de distinção em relação aos sentidos dos quais deriva.

A reflexão contemporânea sobre níveis distintos da crítica tem focado, a partir de perspectivas contrastantes, um desses conceitos multifacetados: a metacrítica. Em um dos sentidos desse termo, França (2014) aprofunda os estudos de Boltanski (2011) para destacar a diferença entre uma crítica mundana e uma metacrítica acadêmica, que parte dos comentários de diferentes atores sociais, refletindo sobre seus pressupostos e lugares de fala. Entretanto, outra definição pode ser apresentada para esse mesmo conceito, destacando não tanto seu ponto de partida, mas seu meio e seu objetivo (Paganotti \& Soares, 2015). Assim, a metacrítica pode ser compreendida como a crítica midiática veiculada pela própria mídia, tratando com especial atenção os critérios adotados para esse julgamento ponderado (tanto da expressão midiática original quanto de seu comentário), sem ignorar a tensão de ocupar um espaço dentro das mesmas engrenagens do maquinário midiático que pretende avaliar.

Para melhor compreender os limites entre as diferentes noções ao redor desse conceito, é necessário questionar: qual a meta da metacrítica? O artigo aborda a possibilidade de se estabelecer uma crítica da cultura midiática por meio da metacrítica e a dificuldade peculiar em até mesmo sugerir uma definição unívoca para o conceito, devido à sua multiplicidade e variabilidade (ainda que seja possível discutir algumas proximidades e filiações comuns a conceitos que parecem diferir, como será realizado posteriormente), apresentando suas aplicações em diversos campos do conhecimento e relacionando-o aos estudos das mídias. Finalmente, o texto propõe a metacrítica midiática como uma noção capaz de aglutinar análises sobre as práticas midiáticas, demonstrando sua pertinência em produções audiovisuais recentes. Ao nos indagarmos sobre os lugares da crítica e as metas da metacrítica, algumas questões norteiam nosso trabalho. Se a meta é tanto um alvo como um desafio para a crítica, o que seria, afinal, aquilo que a crítica da mídia procura? A atribuição de valores e 
critérios avaliativos; a explicitação e correção de equívocos; a desconstrução de intencionalidades pressupostas; a problematização de efeitos e consequências; o questionamento de pontos de vista estabelecidos; a complementação colaborativa entre produtores e receptores; a renovação de estilos e linguagens; a proposição de outros modos de representação, especialmente de grupos minoritários, seriam possíveis respostas a essa busca. De modo mais complexo, outros aspectos se colocam, notadamente se considerarmos a crítica especializada: 1) contribuir para a reflexão e a consolidação das obras analisadas; 2) traduzir as obras para o público e estimular a recepção crítica sobre elas; 3) guiar o mercado e seus modos de realização; 4) iluminar a produção cultural contemporânea e dar visibilidade às obras; 5) estabelecer critérios de análise das obras e de formação do público; 6) interpretar as obras não apenas em seus elementos internos, mas relacionando-as ao contexto político, cultural e social em que estão inseridas.

Essas diversas modalidades, em seu conjunto, corroboram o papel da crítica como instância ao mesmo tempo legitimadora das obras e dos modos como devem ser recebidas. Entretanto, com o advento das tecnologias e de novas sociabilidades a partir delas, a função da crítica é transformada e ela deixa de ser uma voz única na composição de sentidos sobre essas narrativas, expandindo seus limites. Paradoxalmente, por outro lado, a proliferação de produções especialmente audiovisuais - reafirma a importância do exercício crítico para que o público possa se posicionar frente a essa maior quantidade e variedade de obras, renovando o espaço da crítica como aquele que deve estabelecer uma relação ampliada entre elas e seus receptores.

Em sua primeira coluna na seção "Notas de Crítica Literária”, publicada em 7 de janeiro de 1943 no jornal Folha da Manhã (criado em 1925 e que, em 1960, passaria a se chamar Folha de S.Paulo), Antonio Candido (2017) escreve:

Do crítico, espera-se geralmente muita coisa. Antes de mais nada, que defina o que é a crítica para ele. Acho isso muito justo, uma vez que ele é um indivíduo que vai emitir opiniões tendentes, em suma, a explicar uma obra ou um autor. Este aspecto metacrítico do ofício - que é porventura o seu fundamento e o seu mais firme esteio - é, no entanto, às vezes, uma questão de tal modo pessoal, revestindo-se de uma tão necessária imodéstia no seu enunciar-se, que melhor seria pedir ao crítico literário qual a sua ética - quais as imposições que se faz e quais os princípios de trabalho com os quais não transige. O aspecto ético do seu ofício é, sem dúvida alguma, tão importante quanto o primeiro. (para. 1)

Além de uma dimensão avaliativa ou pedagógica, portanto, o ofício da crítica seja ela feita de modo formal ou informal - pressupõe uma ética e deve articular 
os campos da produção e da recepção, refletindo sobre seu fazer e sobre as obras que avalia em pelo menos três planos: o estabelecimento de critérios e valores; a relação com os realizadores; e a renovação das próprias obras, não apenas em termos de conteúdos mas de formatos, dialogando com o entorno em que circulam. No entremeio de tais articulações é que podemos conceber uma crítica da cultura midiática que não leve em consideração apenas as obras (seus elementos internos), tampouco somente os contextos ampliados (suas demandas externas), mas que busque, justamente, o equilíbrio (ou o tensionamento) entre esses polos. No caso da crítica da mídia, ela já se encontra inserida no tecido social e dele não pode ser separada, pois cada um de nós toma parte nessa cultura midiática - 0 lugar da crítica, portanto, inscreve-se no intervalo entre a criação, a circulação e a apropriação desses discursos, ecoando a voz dos receptores e colocando uma questão sobre a atuação do crítico como mediador. Nesse sentido, a crítica não pode desconsiderar os contextos sociais em que é realizada, assumindo sempre uma perspectiva histórica e política, para além de aspectos prescritivos ou normativos.

Ao redor desses circuitos, a crítica da cultura midiática se expande, abarcando a crítica da mídia e a crítica na mídia, cada uma delas desdobrando-se em pelo menos duas vertentes: a crítica especializada ou a crítica acadêmica, ou seja, a crítica como um modo de olhar os objetos presentes nas mídias; e a crítica da mídia sobre a crítica feita na mídia, ou aquela engendrada nas próprias obras produzidas. Assim concebida, à crítica de mídia pode-se atribuir um duplo movimento: por um lado, a realização de "uma análise das mídias que seja de fato crítica" e, por outro, a concepção do "lugar da crítica como desconstrução de discursos cristalizados", sob o risco de termos apenas "análises opinativas ou superficiais que se denominam 'críticas', mas, na verdade, apenas repetem o já sabido sem demonstrar aquilo que afirmam” (Soares \& Silva, 2016, p. 20).

Ao realizar tais movimentos, a crítica da/na mídia amplia os possíveis modos de construção da representação presentes nos discursos midiáticos (os modos de olhar a realidade), transformando os regimes de visibilidade (os modos de dar a ver a realidade) e reconfigurando a partilha do sensível (Rancière, 2012) entre diferentes atores sociais:

Ao fazê-lo, a crítica de mídia se torna também a crítica dos modos pelos quais é construída a representação - ou o visível - e se volta não apenas para aspectos da produção, mas também da recepção e da formação do público, de um público que, como vimos, também participa do circuito da crítica. (Soares \& Silva, 2016, p. 21)

Ao evidenciar possibilidades estéticas e narrativas, apontar a multiplicidades de vozes manifestas nas obras e problematizar discursos e formatos considerados 
hegemônicos, a crítica da/na mídia aponta para outros caminhos nos sistemas de produção e recepção, diversificando e alargando a cultura midiática na qual está imersa e para a qual se volta.

A crítica da mídia sustenta-se, assim, na análise de produções específicas e dos objetos concretos que circulam nos meios de comunicação, pois eles compõem uma espécie de imaginário da cultura midiática e, além disso, conformam um acervo desse imaginário, estruturando as relações sociais e sendo por elas estruturados. Ligada às práticas midiáticas (como se constituem seus discursos e o que geram), dela se espera que aponte possíveis convergências e hibridismos entre os meios, e que estabeleça vínculos comunicacionais com o público e com eventuais contribuições críticas por ele realizadas. Finalmente, a crítica da mídia tem como um de seus pilares não apenas interferir em futuras produções, mas na própria realidade - ou sua relação com os contextos sociais seria esvaziada. Ou seja, para além de uma perspectiva estética, temos uma visada política na crítica da cultura midiática, que se torna, assim, crítica das representações e das mediações culturais nela potencializadas de modo dinâmico e múltiplo.

Observando as práticas midiáticas e visando, por meio delas, construir categorias conceituais para analisar obras específicas, a crítica da mídia interfere ativamente na cultura midiática da qual participa. Às possibilidades de emergência de um efeito crítico, somadas às maneiras pelas quais se expressa a crítica (partindo e falando da mídia), chamamos de metacrítica midiática, contribuindo para a inovação e a renovação das práticas midiáticas em que a crítica se origina (e para as quais ela se volta) e estabelecendo, no ponto de chegada, um novo ponto de partida para a crítica da mídia. A metacrítica, nesse sentido, amplia o alcance da crítica, pois não trata apenas das produções midiáticas mas da crítica feita de dentro delas, ressaltando o caráter relacional e sistêmico das mediações.

Evidentemente, ao tomar a mídia de assalto (já que a considera como seu alvo), ao mesmo tempo em que coabita seus veículos (visto que é transmitida por meio dela), essa forma de metacrítica encontra algumas limitações de difícil resolução. Por um lado, existe um risco de exagero da postura crítica, adotando uma atitude radicalmente autônoma para negar a contraditória situação de dependência própria desse formato de crítica. É o caso da crítica que confunde um de seus pressupostos - a independência - com um fim em si mesmo. Nesse caso, o papel reflexivo da crítica e a necessidade de exposição de seus critérios podem acabar em segundo plano, dando espaço para posições mais radicais ou até mesmo militantes, assumindo como bandeira o ataque contra o sistema midiático para disfarçar que seu autor, afinal, faz parte desse próprio sistema combatido.

Por outro lado, existe o risco oposto de um mergulho muito profundo e quase acrítico no aparato midiático que deveria ser criticado, uma situação 
em que a crítica pode pecar não pelo excesso, mas pela sua falta: é o caso das críticas tão imersas no sistema midiático que passam a se entrincheirar nele, defendendo-o e justificando-o. O crítico parece retribuir o espaço midiático conquistado com um serviço de advocacia de seus contratantes, desmerecendo as críticas apresentadas por outros e opondo-se a qualquer mudança no sistema midiático que compreende, defende e que parece beneficiá-lo.

Em ambos os casos, ignora-se a necessidade de reflexão sobre a própria inserção da crítica nesses meios, ferramenta essencial que as diferencia da proposta de metacrítica apresentada a seguir para evitar tanto a armadilha da militância radical, quanto da defesa institucional. Ainda assim, é inegável que essas duas abordagens viciadas da crítica parecem tentadoras justamente porque apresentam argumentos válidos: em primeiro lugar, a importância de lutar por autonomia para sugerir caminhos alternativos na produção midiática; em segundo lugar, a dificuldade de construir intervenções diretas que superem as limitações de sistemas ariscos à mudança, o que limita a ação concreta da crítica sobre o funcionamento das mídias e sobre a realidade, de modo geral.

Levando esses pontos em consideração, a fim de melhor delinear o conceito de metacrítica, é importante reconstruir parte da história recente de seu uso nos estudos sobre comunicação a partir da sociologia, diferenciando suas manifestações e apropriações por autores que tratam de fenômenos variados, e destacando de que forma suas recorrências ou divergências revelam formas complementares para a análise da crítica da mídia. Por meio dessa análise, encontram-se pressupostos comuns que realinham aparentes distinções conceituais, enfoques e recortes, e reaproximam as conclusões ainda que considerando sentidos diversos para a terminologia ao redor do conceito de metacrítica. Mais do que inspirações de um autor para o outro, destacam-se afiliações em comum: além da gênese de novos conceitos, que carregam para frente o legado das ideias anteriores que ecoam, sem substitui-las, o que se busca é apresentar um alinhamento entre conceitos por vezes paralelos. Nesse sentido, a análise da herança de Boltanski (2011) para essas abordagens ao redor do conceito de metacrítica pode trazer à luz outros dos conceitos originários utilizados por esse autor juntamente com a metacrítica (como a metapragmática e a metalinguagem), o que pode permitir apurar o sentido que este teórico apontava para a meta da metacrítica.

Longe de apresentar uma disputa entre autores e suas respectivas definições, o que se sugere no presente artigo é a importância de que os sentidos ao redor da metacrítica sejam diversificados, respeitando a abordagem crítica sugerida pelo próprio Boltanski (2011) ao denunciar o esforço autoritário de instituições que pretendem estabelecer e difundir noções unívocas para termos polêmicos, 
normalizando e neutralizando sentidos iminentemente políticos e disfarçando contradições sob o aspecto da homogeneidade. Como Boltanski (2011, p. 75) defendia, o objetivo da metacrítica deve ser desconstruir conceitos e revelar sua instrumentalização, destacando o quão instável essas palavras podem se revelar para quem procurar suas origens e mudanças no tempo.

Bakhtin (2010) também considerava que as palavras não podem ser vistas como simples representações da realidade, já que ocultam disputas sociais pelo controle de seus significados. Nesse espaço de confronto ideológico, a palavra não só é usada para representar ideias em conflito, mas também funciona como o próprio campo em disputa, pois se luta também para a definição dos seus significados, das circunstâncias em que deve ser proferida ou controlada, e de quem tem o poder para fazê-lo. Diferentes atores sociais podem, nessa disputa, esforçar-se para tentar "conferir ao signo ideológico um caráter intangível e acima das diferenças de classe, a fim de abafar ou de ocultar a luta dos índices sociais de valor que aí se trava, a fim de tornar o signo monovalente" (p. 48).

Este artigo procura justamente mostrar os diferentes significados que se misturam por trás desse sentido supostamente monolítico do conceito de metacrítica, destacando seus pontos de confluência e como cada uma das formas, ainda que distintas, guardam uma filiação comum, por parentesco, com os sentidos dos quais derivam. Visto que "o signo se torna a arena onde se desenvolve a luta de classes" (Bakhtin, 2010, p. 47), o que se pretende é considerar que um conceito complexo como a metacrítica não pode apresentar uma significação pacificada, sob o risco de ignorar seus diferentes - por vezes complementares, ou até mesmo concorrentes - contextos. Dessa forma, é importante destacar em que circunstâncias e com qual objetivo (ou seja, com qual meta) o conceito de metacrítica é utilizado.

\section{DIFERENTES METAS: METAPRAGMÁTICA, METALINGUAGEM E METACRÍTICA}

Para compreender o sentido proposto por Boltanski (2011) para a metacrítica, é interessante delinear como esse conceito se insere ao lado de outros dois elementos centrais em sua obra (e que se aproximam por partilhar de objetivos e filiações semânticas em comum ao adotar o mesmo prefixo): a metapragmática e a metalinguagem.

Ao avaliar as formas como as críticas são expressas socialmente, Boltanski (2011, p. 61) distingue dois períodos: o primeiro, em momentos de prática da crítica ou da atuação social, que são o foco da abordagem propriamente pragmática; o segundo, em momentos reflexivos que demandam a suspensão 
${ }^{1}$ No original: "depend on factors of uncertainty to create unease by challenging the reality of what presents itself as being, either in official expressions or in manifestations of common sense". Essa e demais traduções dos autores. dessa prática para sua discussão e, portanto, classificados como metapragmáticos. Nos momentos pragmáticos, a interação social rotineira ocorre sem que as regras sociais precisem ser discutidas ou problematizadas; as ações podem ocorrer de forma mais automática e são percebidas de forma naturalizada. Entretanto, em momentos de profunda crise, ou quando o funcionamento das regras de interação social é justamente o alvo da crítica, é necessário que muitos desses pressupostos supostamente naturalizados também sejam passíveis de crítica, suspendendo com isso a ação prática direta para debater as balizas que determinam o que pode ser feito ou discutido. A metapragmática, com isso, é vista como uma ação prática que incide sobre as práticas sociais, uma reflexão que suspende as formas de agir pressupostas, submerge nas suas regras de funcionamento e eventualmente pode superá-las, sugerindo novas regras de interação.

Nesse momento metapragmático, alguns atores podem agir de forma a confirmar o funcionamento das normas, visando preservar a ordem vigente e reduzir o grau de incerteza que emerge em um cenário de questionamento dos pressupostos anteriormente dados como evidentes e que passam a ser alvos de contestação (Boltanski, 2011, p. 61). Em oposição a essas formas de "confirmação", Boltanski (2011, p. 62) contrapõe sistemas que "dependem de fatores de incerteza para criar inquietação para desafiar a realidade do que se apresenta como real, seja em expressões oficiais ou em manifestações de senso comum" que ele define como formas críticas de expressão.

O conceito metapragmático não só é importante para contrastar formas diferentes de tematização de pressupostos que regem a interação social, mas também por apresentar uma definição evidente do que Boltanski considera como crítica: uma forma que coloca em risco a ordem que se apresenta como natural ao suspender a expressão automatizada, questionando seus pressupostos para, com isso, abrir espaço para mudanças que seriam difíceis, se não impossíveis, sem essa reflexão sobre as regras do jogo que demanda sua suspensão. Além disso, esse conceito apresenta um paralelo interessante ao indicar como Boltanski compreende o sentido do prefixo meta, sugerindo uma prática que suspende, reflete e potencialmente supera as práticas sociais - um sentido que se aproxima daquele adotado pelos outros dois pares de metas que veremos adiante.

Uma das formas pela qual a metapragmática pode questionar o funcionamento das convenções sociais se dá pelo fato de que podemos usar da linguagem para debater a própria linguagem - ou seja, a metalinguagem.

Mas a habilidade mais surpreendente dos registros metapragmáticos é o uso que encontramos neles da possibilidade que é característica das linguagens naturais ... 
de falar sobre a própria linguagem sem transformar a linguagem.... Na verdade, o recurso à metalinguagem como um "instrumento da linguagem que serve para falar da linguagem como um objeto" (como Josette Rey-Debove escreve em seu livro sobre esse tema) é o único mecanismo que permite atrair a atenção para a relação entre formas simbólicas e o estado das coisas - uma relação que permanece opaca ou irrelevante no registro prático ${ }^{2}$. (Boltanski, 2011, p. 71)

Ao retomar essa definição de Rey-Debove de metalinguagem como um "instrumento da linguagem que serve para falar da linguagem como um objeto"3, Boltanski (2011, p. 71) destaca que esse é o principal mecanismo - quando não o único - capaz de trazer à luz a normalmente opaca relação entre elementos da ordem social e sua representação simbólica. Ao dar significação para uma relação vista como natural (ou seja, ao suspender uma prática linguística para refletir metapragmaticamente sobre seu funcionamento, questionando suas convenções e sentidos), abre-se espaço para o apontamento de que essa relação não é a única possível, pode ser arbitrária e talvez não seja a melhor ou nem mesmo minimamente adequada. Dessa forma, o sentido de meta, na metalinguagem, pode ser visto também como a reflexividade sobre o meio em que se insere, insinuando alternativas interpretativas e outras possibilidades de ação discursiva.

Boltanski (2011) também destaca o papel das instituições que assumem a função de registro, fixação e difusão dos sentidos que a linguagem apresenta para nosso mundo. Para o autor, muitas vezes esses significados são colocados de forma definitiva, ou seja, apresentando as definições vistas como aceitáveis e estáveis para determinados termos com o objetivo de pacificar ou reduzir as incertezas, ambiguidades ou contradições que possam ser alvo de contestação ou apropriações diferentes (p. 75) - a abordagem de confirmação apresentada anteriormente. Considerando o objetivo do artigo, não é possível ignorar essa questão em particular, levando-nos a um apontamento metapragmático: afinal, o que se procura instaurar é justamente uma contestação sobre o sentido de um conceito que é alvo de incerteza, sugerindo uma nova apropriação para o termo metacrítica a partir de discussões metalinguísticas sobre sua definição em relação a palavras etimologicamente afiliadas.

Com isso, é possível finalmente considerar a definição que Boltanski apresenta para o conceito de metacrítica, que se contrapõe a uma forma de crítica adotada por diferentes atores sociais em seu cotidiano. Uma crítica mais objetiva poderia, assim, ser elaborada por pesquisadores que partem dessas diversas críticas socialmente difundidas e questionam seus posicionamentos e sua relação com o alvo, compondo, então, uma crítica de segunda ordem - ou metacrítica:

\begin{abstract}
${ }^{2}$ No original: "But the most striking feature of metapragmatic registers is the use we find in them of the possibility possessed by natural languages ... of speaking about language itself without changing language. ... In fact, recourse to metalanguage as a language instrument that serves to speak of a language object' (as Josette Rey Debove writes in her book on the subject) is the only thing which makes it possible to turn attention to the relationship between symbolic forms and states of affairs - a relationship that remains opaque or irrelevant in a practical register".

${ }^{3}$ No original: "language instrument that serves to speak of a language object".
\end{abstract}


${ }^{4}$ No original: "we shall say that critical theories of domination are metacritical in order. The position adopted, geared to the critique of a social order in its generality, distinguishes metacritical positions from occasional critical interventions which, from a position of scholarly expertise, call into question, with a view to reparation or improvement, some particular dimension of social relations without challenging the framework in which they are inscribed. But metacritical constructions must also be distinguished from the multiple critical stances adopted by ordinary people who, in the course of political action and/or the disputes of daily life, denounce people, systems or events that are characterized as unjust by reference to particular situations or contexts. In the rest of these talls, when we speak of critique, it is to these socially rooted, contextual forms of criticism that we shall be referring, while reserving the term metacritique to refer to theoretical constructions that aim to unmask, in their most general dimensions, oppression, exploitation or domination, whatever the forms in which they occur".

${ }^{5}$ No original: "theoretical constructions that aim to unmask".
Nós diremos que teorias críticas sobre a dominação são metacríticas em ordem. A posição adotada, considerando a crítica da ordem social de modo geral, distingue posições metacríticas de intervenções críticas ocasionais que, de uma posição de especialização acadêmica, questiona, com um objetivo de reparação ou melhoria, alguma dimensão particular das relações sociais sem desafiar o quadro geral em que elas se inserem. Mas construções metacríticas devem também se distinguir das múltiplas práticas críticas adotadas por pessoas comuns que, no curso de suas ações políticas e/ou em disputas cotidianas, denunciam indivíduos, sistemas ou eventos que são caracterizados como injustos, usando como referência situações e contextos particulares. No resto dessas palestras, quando eu falar de crítica, estarei me referindo a essas formas contextuais de crítica com raízes sociais, enquanto reservarei o termo metacrítica para me referir às construções teóricas que pretendem desmascarar, em suas dimensões mais gerais, a opressão, exploração ou dominação, em quaisquer formas que ocorram ${ }^{4}$. (Boltanski, 2011, p. 6)

A crítica cotidiana, classificada por Boltanski (2011) como uma crítica $\operatorname{com} c$ minúsculo, apresentaria enraizamento social, uma forma contextual de crítica, enquanto a metacrítica, uma forma de Crítica com $C$ maiúsculo, pode ser vista como "construções teóricas que pretendem desmascarar"5 (p. 6) formas de opressão, exploração ou dominação que podem eventualmente ser ignoradas ou deturpadas pelas críticas dos agentes sociais justamente por serem posicionamentos parciais, envolvidos e interessados no conflito de que tratam e que pretendem influenciar. No trecho citado, o autor também diferencia sua metacrítica de outras propostas de intervenção crítica pontuais, que podem inclusive partir de especialistas acadêmicos, mas que somente pretendem reformar, questionar, aprimorar ou reparar pontos específicos de relações sociais problemáticas, ignorando o contexto mais amplo em que se inserem - o que deve ser a função de uma crítica mais complexa, contextualizada e radical, como a metacrítica que assume seu papel verdadeiramente crítico ao correr o risco de alterar as relações sociais de que trata, questionando suas fundamentações.

Após essa baliza teórica entre as três metas de Boltanski (2011), é importante compreender como o conceito de metacrítica insere-se e pode influenciar os debates sobre a crítica da mídia em particular. França (2014), pioneira ao trazer a discussão sobre a metacrítica de Boltanski para o campo da comunicação no Brasil, destaca como essa ideia pode ser fértil para a compreensão da queda na predominância da crítica (e da necessidade de sua retomada) em relação aos estudos de caso mais descritivos e segmentados, uma tendência que dominou as ciências da comunicação em décadas recentes. Em seu estudo, França (2014) 
remonta à tradição da teoria crítica que inicialmente influenciou a pesquisa em comunicação, reconstruindo uma linhagem que se filia à Escola de Frankfurt, os estudos sobre hegemonia de Gramsci e os estudos sobre dominação de Bourdieu do qual Boltanski se aproxima, por ter contribuído em muitas pesquisas conjuntas com seu orientador, mas também se afasta, ao sugerir uma "sociologia pragmática da crítica, voltada para a observação da ação cotidiana dos atores” (p. 108).

A abordagem de Boltanski (2011) contrasta com a tradição da sociologia crítica, que revelava a incapacidade dos agentes sociais em resistir ou influenciar os muitos mecanismos de opressão de diferentes instituições ${ }^{6}$ (entre as quais, mas não somente, a mídia), e reconhece um papel mais ativo para os sujeitos, cuja atuação passa a ser o foco central da análise acadêmica. Assim, a sociologia pragmática da crítica analisaria a difusão social dos mecanismos de crítica, o que se critica na sociedade, e de que modo. Com isso, Boltanski distinguiria uma crítica difundida por diferentes atores na sociedade, que passaria então a ser coletada, analisada, teorizada, contextualizada e desconstruída por pesquisadores que formulariam, por sua vez, uma crítica das críticas - ou metacrítica:

A crítica dos indivíduos e a crítica social configuram, para o autor, dois conceitos distintos, que ele nomeia crítica e metacrítica. O conceito de crítica se refere às críticas isoladas, desenvolvidas por indivíduos a partir de sua própria existência; ela é localizada e específica. Já a metacrítica é uma crítica de segundo grau, que se apoia nas críticas individuais, se alimenta delas e as reúne, constituindo-se e elevando-se enquanto uma crítica de ordem social. Ele é, assim, uma construção teórica e objetiva desvelar a opressão, a exploração, a dominação de uma sociedade ou grupos sociais. (França, 2014, p. 112)

Desse modo, seria necessário diferenciar uma crítica dos atores que se encontram imersos nas disputas da sociedade - e que podem tematizar a opressão, mas nem sempre considerar seus pressupostos ou contexto de funcionamento, e tampouco tratar de forma desinteressada uma questão que os afeta diretamente - de uma crítica com exterioridade, que pode ser apresentada por um observador distanciado, capaz de descrever ou julgar com objetividade uma realidade justamente por encontrar-se fora dela - como o caso de um pesquisador acadêmico, por exemplo (França, 2014, p. 112). A metacrítica, nesse sentido, se alimenta, mas também se destaca, da crítica cotidiana, tomando-a como ponto de partida para sua contextualização, desconstrução, crítica e eventual superação, separando a crítica especializada daquela advinda de grupos sociais.
${ }^{6}$ Entre os objetos de estudo de Boltanski (2011) - ou seja, as instituições que eram alvo de crítica de diferentes atores sociais -, destacam-se desde testes como processos seletivos para vagas profissionais ou universitárias, até entidades que pretendiam definir critérios para a continuidade de gestações. 


\section{UM NOVO SENTIDO PARA METACRÍTICA NOS ESTUDOS DA MÍDIA}

Outra vertente pretende apresentar mais um sentido para esse mesmo conceito de metacrítica. Para isso, devemos considerar a reflexividade do prefixo meta, que também estava presente nos sentidos de metapragmática e metalinguagem discutidos por Boltanski (2011). Ao descrever a etimologia do prefixo grego, Cunha (2010) destaca que a partícula "expressa as ideias de comunidade ou participação, mistura ou intermediação e sucessão” (p. 423). Por esse caminho semântico, procura-se retomar o sentido originário da meta como uma forma de agregação mediada, que também estava presente no conceito de Boltanski (2011). Apesar de o autor não discutir a origem do conceito, sua abordagem se encaixa nesse sentido ao caracterizar a metacrítica como uma crítica que sucede as críticas partilhadas nas comunidades sociais, ainda que, indiretamente, pretenda diferenciar-se - e não se mesclar - nesse espaço comunitário.

Por outro lado, não é possível ignorar o sentido latino para o substantivo meta, que se distancia do prefixo grego. Cunha (2010) destaca o duplo significado contraditório desse termo, que pode se referir tanto a "baliza, limite, barreira" quanto a "alvo, objetivo" (p. 423). Dessa forma, a meta pode tratar do que se busca atingir e das adversidades que dificultam esse intento. Considerando os diversos significados para meta, é possível sugerir outro sentido para metacrítica: não só uma crítica agregadora, mediada e reflexiva, que procura criticar a crítica (o sentido de Boltanski), mas também uma que considere a contradição de sua inserção no mesmo meio que procura criticar - uma crítica do juízo crítico que não ignore o fato de que seu objetivo (a crítica) é também um obstáculo a superar.

Como vimos, a potência metacrítica não advém simplesmente do fato de uma produção midiática (seja impressa, sonora ou audiovisual) ser objeto da crítica ou criticar os meios de comunicação, mas do fato de incluir a si própria (sua concepção e sua audiência) no cenário que está sendo criticado. Ao assumir que nem toda crítica é metacrítica, torna-se necessário indagar sobre como ocorre a crítica $d a$ mídia na mídia (ou como um produto midiático faz a crítica à própria mídia); apontar alguns critérios mobilizados nessa crítica; e identificar as novas formas de expressão que dela surgem. Por não se limitar apenas às obras, mas aos circuitos de produção e recepção, a metacrítica busca fazer a crítica da mídia e pretende ir além dela, reconhecendo-se como parte de seus mecanismos e dando ao público as ferramentas para que também possa exercitar a crítica de modo sistemático (e não apenas em manifestações difusas ou pulverizadas nas redes sociais).

Esse cenário se torna mais complexo ao considerarmos particularmente a mídia, já que grande parte da crítica sobre os meios de comunicação, afinal, é 
publicada também por meios de comunicação - muitas vezes pelo próprio veículo de que se trata, como no caso de comentários, cartas de leitores ou ombudsmen (Braga, 2006). Não se pode desprezar, evidentemente, as interações comunicativas imediatas (presenciais e orais, por exemplo), que não dependem de um suporte de midiatização, como o caso da "interação face a face" (Thompson, 2008, p. 17), e que também podem apresentar críticas sobre as mídias em diálogos cotidianos. Entretanto, o que se pretende destacar é o caso das expressões comunicativas que superam essas manifestações efêmeras, de difícil registro e impacto limitado, ou seja, comunicações que ocupam o espaço midiático ao apresentar suas críticas à própria mídia.

Nesse caso, temos não só uma crítica da mídia - ou seja, que tem como finalidade tratar de produtos midiáticos - mas também a crítica na mídia veiculada por um meio de comunicação (Paganotti \& Soares, 2015, p. 37). Com isso, resgatamos o duplo sentido latino do termo meta: a metacrítica trata tanto do objetivo (crítica da mídia) quanto da baliza (crítica na mídia) da crítica. Ao mesmo tempo, essa crítica não pode ignorar seus limites e barreiras - seu aspecto ético -, outro sentido da partícula meta. É necessário considerar a inserção incômoda da crítica no meio das engrenagens midiáticas que pretende desconstruir (Paganotti \& Soares, 2015, p. 51).

Outras formas de crítica podem expressar somente uma dessas características: uma palestra acadêmica que critique a representação de uma novela sobre a violência policial, por exemplo, terá a mídia como meta, tomando-a como seu "alvo, objetivo" (Cunha, 2010, p. 423); já uma crítica veiculada em um jornal sobre abusos cometidos por agentes da polícia tomará a mídia como seu espaço para veiculação apropriada, e adotará as convenções de linguagem e formato próprias desse meio - ou seja, a mídia será "baliza, limite" (Cunha, 2010, p. 423) para sua expressão.

É possível unir ambas as formas de crítica em uma só, adotando uma crítica da mídia na mídia, por exemplo publicando em uma revista uma crítica sobre uma música que é considerada ofensiva. Ainda assim, essa forma de crítica da/na mídia não será, necessariamente, uma metacrítica, processo mais específico que precisa também refletir criticamente sobre sua inserção no espaço midiático e expor seus critérios de avaliação. No exemplo anterior, seria o caso de refletir se a crítica contra a música ofensiva não acabaria por dar-lhe ainda mais divulgação e notoriedade (ou seja, refletindo sobre a inserção da crítica no sistema midiático que pretende criticar), justificando a escolha com os critérios adotados para a formulação da crítica, que considera mais importante discutir uma situação problemática do que ignorá-la (ou seja, apresentando os critérios que balizam a avaliação crítica de forma explícita). 
${ }^{7}$ No original: “Choice involves agency. Agency involves the possibility of challenge and refusal. This is not say that we can walk away from our media-saturated culture. Manifestly we cannot. But we can begin to understand it and in that understanding take responsibility for it. We can then challenge and change it".
A metacrítica coloca-se, dessa forma, como um modo singular de aproximação às práticas midiáticas, pois se insere naquilo que relata de maneira crítica, ou seja, rompendo e problematizando essa inclusão. É, portanto, de forma fluida que a metacrítica se estabelece, mesclando várias camadas críticas em suas narrativas e constituindo-se, assim, como um entre-lugar que aponta interseções e passagens entre os meios. Não apenas a produção de textos, colunas ou análises empreendem uma crítica sobre as mídias, mas também os programas, produtos e obras que nelas se apresentam. Nesse espaço intermediário, a relação com o público (seja ele leitor, ouvinte ou espectador) também é fundamental, pois é ele quem recria as obras por meio de interpretações que se influenciam mutuamente (tanto aquelas de profissionais, como as do público em geral) ainda que não se torne, necessariamente, produtor de novas obras, como se esperava que ocorresse nas mídias digitais, supostamente mais interativas.

A partir dessa concepção, a crítica das mediações também pode ser pensada como uma metacrítica, implicando no agenciamento dos sujeitos como corresponsáveis pelos processos comunicacionais por meio de convocações enunciativas ligadas à práxis comunicacional, já que aqueles que fazem a crítica também participam desse aparato midiático:

Escolha envolve agência. Agência envolve a possibilidade de desafio e recusa. Isso não quer dizer que podemos nos distanciar da nossa cultura saturada de meios de comunicação. Claramente, não podemos. Mas nós podemos começar a entendê-la e com essa compreensão nos responsabilizar por ela. Podemos, então, desafiá-la e mudá-la ${ }^{7}$. (Silverstone, 2002, p. 777)

Se a comunicação evoca o comum, a diversidade de representações e interpretações são articuladas nessa perspectiva, atestando que a relação crítica com a mídia - seja por parte de produtores, especialistas ou do público - passa pelo desafio da mediação que constitui os meios e visa transformá-los. Ao tratar desse tipo particular de crítica midiática, o conceito de metacrítica torna-se instrumental por destacar as circunstâncias nas quais essa crítica explicita a situação incômoda de criticar a mídia ao mesmo tempo em que se veicula essa crítica por um meio de comunicação.

Mais uma vez, esse tipo de crítica midiática não ocorre em todas as circunstâncias, o que dá ainda mais importância à análise dos casos excepcionais em que essa tensão de sitiar a mídia usando seus próprios instrumentos não é ignorada. Essa consciência sobre a ocupação do corpo midiático pode se dar de forma parasitária, mimetizando os mesmos mecanismos viciados de espetacularização 
adotados pela mídia que se pretende denunciar, ou pode se apresentar de forma inovadora e reflexivamente crítica: não apenas crítica em seu conteúdo, mas em seu formato. Essa abordagem segue a defesa de Fuchs (2010) de que meios de comunicação só podem ser considerados como verdadeiramente críticos ao apresentarem discursos e narrativas alternativos, que realmente difiram do tradicionalmente adotado pelas mídias.

Se o espaço da crítica é canalizado nas mídias, elas não apenas fazem parte daquilo que criticam mas, ainda, inserem-se nas análises propostas tanto em termos de conteúdos como de formatos. Portanto, também eles devem ser críticos, ou seja, as instâncias apontadas para a crítica da/na mídia articulam não apenas as temáticas e enfoques, mas incluem as formas expressivas e estéticas dessas produções. Ao considerarmos a narrativa como um modo de lidar com o mundo por meio de fabulações (ficcionais ou factuais) construídas na linguagem, podemos atribuir às diversas produções midiáticas uma visada política, seja na chave do entretenimento ou da informação, por meio da busca por inovações.

Retomando as definições de transparência e opacidade propostas por Xavier (2008), temos que a primeira produz como efeito de sentido a apreensão direta da realidade ( sem mediação) e a segunda, ao contrário, explicita em sua construção as diversas camadas presentes nos discursos. Destacamos, nesse momento, a aproximação ao conceito de mediação de Silverstone (2002), ainda que em outra ordem, pois ao afirmar que a crítica da mídia deve buscar a compreensão dos sistemas de produção e recepção em que circulam as obras analisadas, considerando o caráter por vezes desigual das diversas significações e reapropriações operadas pelos realizadores ou pelo público, temos que as mediações se tornam cada vez mais expandidas e múltiplas. $\mathrm{Na}$ definição de metacrítica midiática proposta no artigo, podemos afirmar que a ficção - pensada como instrumento de transformação da sociedade por meio de formas narrativas - que revela suas estratégias discursivas assume o risco da crítica, enquanto aquela que se oculta enquanto tal, pretendendo-se totalizante, esvazia tal potencial.

Nesse sentido, a consciência da crítica da/na mídia só pode ser metacrítica ao refletir também sobre o modo como a crítica será apresentada, evitando os recursos apelativos e simplificadores adotados pelos meios de comunicação que pretende denunciar. Portanto, não basta para a metacrítica "nunca ocultar suas relações contraditórias e seu comprometimento (em todos os sentidos desse termo) com a mídia que disseca, denuncia e de que depende" (Paganotti \& Soares, 2015, p. 52), já que a crítica pode se considerar comprometida por estar contaminada 
de certa forma pelos meios de comunicação em que é veiculada, mas essa mesma crítica deve se lembrar que esse comprometimento pode significar exposição ao risco ou a causa de um dano. Essa consciência problematizante pode ser caracterizada como uma postura reflexiva: a crítica não só apresenta uma reflexão sobre a mídia, mas deve levar em consideração até que ponto aceita refletir os modos de representação adotados pela mídia. Sem essa força destrutiva e criativa, a crítica acabaria condenada à denúncia vazia e hipócrita ou à servil domesticação, em um estéril reforço do que é midiatizado.

A reflexão pode apresentar-se, inclusive, de forma autocrítica, abrindo espaço para a crítica realizada pelos próprios produtores midiáticos, que aceitam refletir sobre os limites de sua atuação, suas falhas ou inadequações, quebrando as expectativas sobre a distinção entre quem é o alvo e o agente da crítica (Soares \& Paganotti, 2016). Seja de forma autocrítica ou não, a metacrítica revela as práticas midiáticas (próprias ou de outros veículos de comunicação) que podem ser problemáticas, refletindo sobre seus impactos negativos. Essa reflexividade pode, assim, ser também transposta didaticamente para seu público: ao dissecar a forma como a mídia é produzida, incentiva uma melhor recepção por parte do público, que pode identificar seus vícios e demandar abordagens mais complexas, contextualizadas e relevantes (Paganotti \& Soares, 2017).

Mas o principal diferencial, em contraste com a proposta original de metacrítica de Boltanski (2011), é que essa forma de ação crítica não pressupõe uma clivagem entre um espaço acadêmico de metacrítica em relação à prática social de crítica cotidiana, realizada pelos indivíduos ou por atores da própria mídia. Nesse sentido, não se reserva um espaço especial para a crítica de especialistas e pesquisadores que, distantes da tribuna pública, coletariam e processariam expressões difundidas socialmente para, então, produzir uma nova crítica mais sofisticada. Pelo contrário, o que se procura destacar é a contiguidade entre essas esferas acadêmicas e sociais, que encontram limites bastante difusos em uma cultura midiática cada vez mais englobante, o que não permite o isolamento acadêmico ou a desconsideração de outras modalidades da crítica ou outros estratos sociais.

Para isso, enfatiza-se o sentido comunitário de "participação, mistura ou intermediação" do prefixo grego meta, considerando que a cultura das mídias une os diferentes atores e que não é tão simples diferenciar as reflexões acadêmicas das práticas sociais - o que podemos considerar como uma abordagem de integração midiática que difere substancialmente da metacrítica apresentada originalmente por Boltanski (2011). Entretanto, de certa forma, esse sentido 
retoma parcialmente a reflexão do próprio autor (p. 21) sobre a difusão dos saberes universitários, que já destacava que muitas das críticas acadêmicas encontram inserção social ao serem apropriadas por agentes culturais no debate público, devido à expansão do ensino universitário em diferentes camadas da sociedade - o que ajuda a ampliar o número de indivíduos que conhecem conceitos e práticas originários da academia - e da difusão de conhecimentos científicos por meio de veículos da mídia - que entrevistam especialistas para apresentar suas visões sobre temas de interesse público ou divulgam os resultados de suas pesquisas.

Não apenas o conhecimento universitário se espalha entre os sujeitos: também a capacidade de apresentar críticas contextualizadas, inovadoras e relevantes está presente entre membros do público e de agentes midiáticos que rivalizam com os pesquisadores acadêmicos em seus conhecimentos sobre esse campo, e podem até mesmo superá-los devido à maior facilidade de comunicação de suas críticas para o público geral. Ao integrar as críticas difundidas pela mídia, passa a ser fundamental destacar como essas críticas apresentam seus julgamentos - e de que forma explicitam seus critérios ou debatem as escolhas adotadas por outros produtos midiáticos. Nesse sentido, a metacrítica passa a enfocar uma análise criteriosa não só no sentido de detalhar os processos adotados pela crítica, mas também por analisar seus próprios critérios. Pode ser considerado uma forma de metacrítica toda crítica que atua como "juiz dos jurados, críticos dos que não sabem criticar” (Paganotti \& Soares, 2015, p. 49), ou seja, a crítica de como se faz a crítica.

Ampliando alguns dos elementos apontados no início do artigo, a metacrítica pode analisar diferentes camadas da crítica: a crítica que foca o conteúdo e o formato de produtos midiáticos, considerando abordagens estéticas ou políticas; a crítica que trata do processo de midiatização e de como produtos individuais inserem-se em uma lógica mais ampla de estratégias para representação de conflitos e mobilização de atenção; ou até mesmo uma análise sociológica para além da mídia, tratando de características mais amplas de nossa sociedade e de como elas podem ser influenciadas ou determinantes para a mídia em particular (Paganotti \& Soares, 2015, p. 49). Independentemente de qual método de crítica seja adotado, o que estaria em jogo em uma análise metacrítica é justamente a explicitação desses critérios de análise, que não podem ser tomados como algo evidente. Ao nomear e explicar os métodos de análise e crítica, abre-se novo espaço para contestação, evidenciando que as opções adotadas são, afinal, escolhas - e, portanto, passíveis de transformação. 


\section{CONCLUSÃO: UMA METACRÍTICA INTEGRADA, REFLEXIVA E CRITERIOSA}

A fim de demonstrar as proposições elencadas, é importante retomar brevemente alguns exemplos de abordagens metacríticas em produções audiovisuais recentes, apontando para um campo profícuo de pesquisas que desenvolvem análises baseadas em distintas aproximações desse conceito (Paganotti \& Soares, 2015, 2017; Soares \& Paganotti, 2016, 2018). Por meio de exemplos variados, as obras nomeadas a seguir carregam alguns traços em comum e delineiam o que se pode chamar de "dispositivos metacríticos" (Monteiro \& Cánepa, 2018, p. 2): o programa semanal televisivo Profissão repórter (Kamel \& Barcellos, 2006-), que aborda os bastidores da reportagem ao mesmo tempo que produz grandes reportagens temáticas; a série televisiva de ficção científica Black mirror (Jones \& Brooker, 2011-), que aborda em diversos episódios a presença das telas virtuais, entre elas a televisão, no cotidiano; a série televisiva The newsroom (Poul, Rudin, \& Sorkin, 2012-2014), que mimetiza uma sala de reportagem ficcional e recria reportagens de acontecimentos jornalísticos verídicos; o filme O âncora 2: tudo por um furo (Apatow, Farrell, \& McKay, 2013), que retrata a produção de um noticiário televisivo convencional por meio da atuação de seu âncora, mostrando como o programa caminha de um formato tradicional para outro de apelo sensacionalista.

Não podemos desconsiderar as singularidades de cada um desses artefatos no que diz respeito aos gêneros narrativos audiovisuais, formatos e canais de veiculação. O filme $O$ âncora 2: tudo por um furo (Apatow et al., 2013), por exemplo,

configura modos de articulação da perspectiva metacrítica distintos de uma série como The newsroom (exibida por um canal de TV por assinatura associado ao arrojo de suas produções, a HBO), no qual um eventual recurso ao humor parece se filiar a uma matriz oposta à do roteiro de Will Farrell e Adam McKay. (Monteiro \& Cánepa, 2018, p. 2)

De maneira semelhante, ao filiar-se a certas estratégias reflexivas ou autorreflexivas do documentário, o programa jornalístico Profissão repórter "ao mesmo tempo que abre todo um campo de possibilidades para o uso metacrítico da linguagem audiovisual, também acaba por lhe impor um conjunto de restrições em função do caráter broadcast da emissora que o veicula" (Monteiro \& Cánepa, 2018, p. 2), diferentemente de Black mirror (Jones \& Brooker, 2011-), série exibida pelo Channel 4, uma rede de televisão britânica de serviço público, ainda que comercialmente autossuficiente, com compromisso de apresentar conteúdo diversificado e de qualidade, a exemplo de outras emissoras públicas europeias. Ainda que tais divergências sejam determinantes para a compreensão dessas produções, nelas observamos estratégias metacríticas convergentes. 
Além de serem veiculadas exatamente nos meios que criticam (televisão e cinema), as quatro produções têm em comum serem feitas em formato audiovisual; tratarem da televisão e de algum aspecto referente ao jornalismo; reconstituírem em suas narrativas ficcionais programas televisivos informativos ou factuais; realizarem uma abordagem social e política da relação atual com as tecnologias de comunicação; inserirem a presença e participação do público em suas narrativas. Mais importante, em termos estilísticos e conceituais, todas assumem a opacidade de seus discursos ao proporem o desvelamento ou de seus bastidores, ou dos modos pelos quais são criados os programas televisivos. Um outro ponto aproxima seus discursos: a postura crítica em relação a essa produção e, mais do que isso, em relação à visão anterior que assumia como transparentes as imagens audiovisuais, isolando os profissionais que as produziam das pessoas que as consumiam.

Evidentemente, as obras mencionadas anteriormente não compõem uma lista fechada nem exaurem os exemplos possíveis de obras metacríticas. Essas produções apresentam um panorama inicial, fruto de pesquisas anteriores sobre a possível fertilidade desse conceito como ferramenta de análise midiática, visto que obras bastante diversas apresentam momentos que podem ser avaliados como práticas da proposta de metacrítica discutida neste artigo. Os elementos que as unem - a explicitação dos critérios de avaliação que fundamentam a crítica, a inserção nos meios de comunicação que pretendem criticar e uma reflexão sobre essa proximidade com o que criticam, critérios para sua inclusão como exemplos representativos dessa prática - sinalizam um possível recorte para pesquisas que procurem avaliar produtos midiáticos que adotam os três pilares metacríticos (critérios, integração e reflexão) sugeridos no trabalho.

Cada uma dessas obras apresenta a tríade de explicitação dos critérios, integração midiática e reflexão sobre seu lugar de fala. O jornalístico brasileiro Profissão repórter (Kamel \& Barcellos, 2006-) abre espaço para que seus jornalistas expliquem suas escolhas, refletindo sobre o distanciamento entre repórteres e suas fontes e subvertendo essas posições, permitindo que os entrevistados questionem de forma direta e incômoda seus repórteres (Soares \& Paganotti, 2016). No distópico seriado inglês Black mirror (Jones \& Brooker, 2011-), um dos protagonistas critica os métodos dos juízes de um programa de calouros que explora a miséria alheia, mas é confrontado com um irrecusável convite para ocupar ele mesmo um espaço nessa mídia de entretenimento, adotando uma postura ambígua de crítica sobre a mesma mídia em que se insere (Paganotti \& Soares, 2015). Na série dramática norte-americana The newsroom (Poul et al., 2012-2014), os personagens criticam erros da imprensa e defendem critérios ideais para coberturas jornalísticas, ao mesmo tempo em que lutam por uma precária autonomia em um canal com 
interesses econômicos e políticos (Paganotti \& Soares, 2017). A comédia filme O âncora 2: tudo por um furo (Apatow, Ferrell, \& McKay, 2013) adota, ironicamente, os mesmos exageros que condena, expondo ao ridículo o processo de racionalização que equipara o sensacionalismo televisivo com o nonsense cômico praticado pelo filme (Soares \& Paganotti, 2018).

Em todos os casos, mais do que se tratarem de diferentes conteúdos midiáticos audiovisuais com formatos e objetivos distintos, o que aproxima esses produtos e os insere na presente reflexão é justamente a cautela da crítica em uma tripla exposição: dos seus critérios, do seu espaço e dos seus eventuais conflitos de interesse.

A resistência à exibição ou à revelação dos modos de funcionamento da produção audiovisual estabelecia uma espécie de deferência (ou condescendência) mágica, que assegurava certo controle e convencimento do público justamente pelo desconhecimento dessas estratégias narrativas. Ao tornar-se conhecedor de técnicas e estilos dos programas a que assiste, o público assume mais poder e capacidade de interferência nessas produções. No caso do jornalismo - não por acaso o locus comum a essas obras -, o ocultamento de seus bastidores costuma ser ainda mais radical. Prova disso é a ausência de making of de produções jornalísticas, que proliferam quando se trata de obras ficcionais. A ironia de tal postura é que, na chave informativa, programas voltados para a denúncia e a vigilância de questões sociais e políticas não se deixam acompanhar de modo crítico, escondendo suas falhas e equívocos (muitas vezes presentes ao se mostrar os bastidores). Aglutinando esses e diversos outros aspectos da produção audiovisual a partir da segunda década dos anos 2000 - que circula na televisão e no cinema, mas é largamente consumida em sites da internet ou em redes sociais -, as produções referidas mostram como algumas práticas antes renegadas aos bastidores passam a ocupar o palco central da cena televisiva ou a tratar da televisão de modo crítico, autocrítico e, como defendemos no artigo, metacrítico.

Como apontamos, não é possível ignorar a tensão social no caso de expressões midiáticas que pretendem criticar justamente os processos comunicacionais nos quais o próprio emissor da crítica encontra-se inserido. Da mesma forma, considerando-se a abordagem de Boltanski (2011) sobre a possibilidade de crítica de formas de representação da linguagem como um elemento estável, com definições imutáveis e naturalizadas, o artigo procurou mostrar sentidos divergentes para o conceito de metacrítica, considerando as balizas dos conceitos de metapragmática e metalinguagem. No processo, foi necessário discutir metalinguisticamente os sentidos desses termos, suspendendo de forma metapragmática sua atuação prática para considerar o sentido dessas abordagens anteriormente naturalizadas. 
Desse modo, e seguindo mais uma vez a abordagem de Boltanski (2011), não se pode esperar a pacificação de um único significado para o conceito de metacrítica. Pelo contrário, deve-se estar aberto para o dissenso, considerando outros sentidos e questionamentos sobre a forma instável adotada para a presente definição, pois ela não pode ser vista como a formulação exclusiva, com maior legitimidade ou mais adequada, afinal, é uma abordagem entre outras, que podem ganhar maior ou menor prevalência no seu uso pelo público. O que se defende, neste trabalho, é a importância de apresentar os critérios adotados para a conceituação dessa forma de crítica, a forma como ela se insere entre outras críticas e outras meta-abordagens, e uma reflexão sobre sua própria capacidade de transformação. Essas eram justamente as três abordagens metacríticas definidas na seção anterior, que pretendem complementar o conceito de Boltanski (2011): integração de perspectivas midiáticas (evitar o descolamento de visões acadêmicas ante a crítica difundida na sociedade e na própria mídia), reflexividade (autocrítica sobre a inserção da crítica nos meios de comunicação de que trata) e análise criteriosa (não só uma análise minuciosa, mas também a crítica dos critérios adotados em julgamento).

É importante destacar que a primeira proposição - a integração midiática - diverge da abordagem metacrítica de Boltanski (2011), que presumia justamente uma construção da crítica a partir das enunciações que circulavam socialmente, mas que demandariam uma reflexão distanciada de pesquisadores desengajados. Também é necessário apontar que as outras duas abordagens sugeridas são, de certa forma, uma estratégia para incorporar conceitos discutidos por Boltanski (2011) em sua obra sobre a crítica, mas com outras metas: a reflexividade demanda uma suspensão da prática comunicativa para discutir sua incômoda inserção dentro dos processos midiáticos que pretende criticar, focando as regras de funcionamento da comunicação como um todo de modo metapragmático, da mesma forma como a análise rigorosa adota fatalmente mecanismos da metalinguagem ao discutir a composição do discurso da crítica e de seus critérios. Acreditamos que discutir os diferentes sentidos da metacrítica e de outros conceitos afins, como a metapragmática e a metalinguagem, é fundamental para a crítica da cultura midiática e sua desafiadora inserção dentro das próprias estratégias discursivas, disputas por representação e lutas por reconhecimento que pretende abordar. $\mathbf{M}$

\section{REFERÊNCIAS}

Apatow, J. (Produtor), Ferrell, W. (Produtor), \& McKay, A. (Produtor \& Diretor). (2013). O âncora 2: Tudo por um furo [Filme cinematográfico]. Estados Unidos: Apatow Productions, Gary Sanchez Productions. 
Bakhtin, M. (2010). Marxismo e filosofia da linguagem: Problemas fundamentais do método sociológico da linguagem. São Paulo, SP: Hucitec.

Boltanski, L. (2011). On critique: A sociology of emancipation. Cambridge, Inglaterra: Polity Press, 2011.

Braga, J. L. (2006). A sociedade enfrenta sua mídia: Dispositivos sociais de crítica midiática. São Paulo, SP: Paulus.

Candido, A. (2017, 12 de maio). Ouverture. Folha de S.Paulo. Recuperado de http://bit.ly/2MwWq05 (Artigo original publicado em 1943)

Cunha, A. G. da (2010). Dicionário etimológico da língua portuguesa (4a ed.). Rio de Janeiro, RJ: Lexikon.

França, V. V. (2014). Crítica e metacrítica: Contribuição e responsabilidade das teorias da comunicação. MATRIZes, 8(2), 101-116. doi: 10.11606/issn.19828160.v8i2p101-116

Fuchs, C. (2010). Alternative media as critical media. European Journal of Social Theory. 13(2), 173-192. doi: 10.1177/1368431010362294

Jones, A. (Produtora), \& Brooker, C. (Produtor \& Criador). (2011-). Black mirror [Série televisiva]. Reino Unido: Zeppotron (2011-2013), House of Tomorrow (2014-).

Kamel, A. (Diretor responsável), \& Barcellos, C. (Criador \& Diretor). (2006-). Profissão Repórter [Série jornalística televisiva]. Rio de Janeiro, RJ: Rede Globo de Televisão.

Monteiro, T. L., \& Cánepa, Laura L. (2018, junho). Relato crítico. Texto apresentado no XXVII Encontro Anual da Compós, Belo Horizonte, MG.

Paganotti, I., \& Soares, R. L. (2015). Metacrítica midiática: Reflexos e reflexões das imagens em Black mirror. In R. L. Soares, \& M. R. Gomes (Orgs.), Por uma crítica do visível (pp. 37-53). Recuperado de http://bit.ly/2MvIi7n

Paganotti, I., \& Soares, R. L. (2017). Fabulação, reconstrução e mediação (meta) crítica no seriado Newsroom. In M. Serelle, \& R. L. Soares (Orgs.), Mediações críticas: Representações na cultura midiática (pp. 81-96). Recuperado de http://bit.ly/2jQzvB0

Poul, A. (Produtor), Rudin, S. (Produtor), \& Sorkin, A. (Produtor \& Criador). (2012-2014). The newsroom [Série televisiva]. Estados Unidos: HBO Entertainment.

Rancière, J. (2012). O espectador emancipado. São Paulo, SP: Martins Fontes.

Silverstone, R. (2002). Complicity and collusion in the mediation of everyday life. New Literary History, 33(4), 761-780. doi: 10.1353/nlh.2002.0045

Soares, R. L., \& Paganotti, I. (2016). 'Eu posso fazer uma pergunta pra você?' O repórter contra a parede. In C. Barcellos (Org.). Profissão Repórter 10 anos: Grandes aventuras e grandes coberturas (pp. 361-377), São Paulo, SP: Planeta. 
Soares, R. L., \& Paganotti, I. (2018). Sob o risco da crítica: a busca pela audiência no filme Tudo por um furo. In R. de L. Soares, \& G. Silva (Orgs.), Emergências periféricas em práticas midiáticas (pp. 11-25). São Paulo, SP: ECA-USP. Recuperado de http://bit.ly/2lqdl9f

Soares, R. L., \& Silva, G. (2016). Lugares da crítica na cultura midiática. Comunicação, Mídia e Consumo, 13(37), 9-28. doi: 10.18568/cmc.v13i37.1140 Thompson, J. B. (2008). A nova visibilidade. MATRIZes, 1(2), 15-38. doi: 10.11606/ issn.1982-8160.v1i2p15-38

Xavier, I. (2008). O discurso cinematográfico: Opacidade e transparência (4a ed.). São Paulo, SP: Paz e Terra.

Artigo recebido em 14 de agosto de 2018 e aprovado em 8 de abril de 2019. 